ISSN: $2219-8229$

E-ISSN: 2224-0136

Founder: Academic Publishing House Researcher

DOI: $10.13187 /$ issn.2219-8229

Has been issued since 2010 .

European Researcher. International Multidisciplinary Journal

UDC 002.53+004.65+004.62/.63+338.2

\title{
Prognostic Model for Estimation of Innovative Activity Factors of Regions by Example of the Patenting Data Based on Cognitive map Modeling*
}

\author{
${ }^{1}$ Anastasiia Suslova \\ 2Leonid Mylnikov \\ ${ }^{3}$ Bernd Krause
}

\begin{abstract}
${ }^{1}$ Perm National Research Polytechnic University, Russia
7, Professora Pozdeyeva str., 614013 Perm

E-mail: suslovaanastasia@gmail.com

${ }^{2}$ Perm National Research Polytechnic University, Russia

29, Komsomolsky avenue, 614990 Perm

E-mail: leonid@pstu.ru

${ }^{3}$ Anhalt University of Applied Sciences, Germany

Postfach 1458, 06354 Koethen (Anhalt)

E-mail: bernd.krause@inf.hs-anhalt.de
\end{abstract}

Abstract. An approach to management of semi-structured scientific research process on the basis of dynamic cognitive map is considered. The approach takes into account interconnections of factors that influence innovative activity and is based on analysis of the following measurable parameters: research activity, innovative activity by branches of industry (applied research), number of developments (applications), demand for technology, geographical spreading, and potential efficiency of innovation.

Keywords: cognitive map; model; forecast; innovative activity; factor; patent.

\section{Introduction}

Today technological achievements and breakthroughs have become possible thanks to experience and scientific achievements. There is a trend of growing expenditures in financing of the modern scientific researches and developments. In leading countries this growth can take the lead over economic growth [9].

Forecasting allows to estimate the prospects of idea and can be considered from different points of view. First point of view is forecasting of research activities, demand in technologies, geographical spreading, financial support etc. Statistical data from patent, abstract and other databases are used for these purposes. The second point of view is forecasting of innovative projects parameters $[1,2]$.

Thereby there is a necessity in monitoring of other teams of researchers activity and alternative approaches to solving problems. In practice this means that working only in narrow

\footnotetext{
* From 23.06.2013 on 01.07.2013 Perm National Research Polytechnic University (PNRPU) in collaboration with the University of Applied Sciences (UAS) Anhalt (Germany) held an International summer school "Information Management". During the school were conducted master classes by leading professors of UAS Anhalt, UAS Hamburg, PNRPU, Bauman Moscow State Technical University. Perm and German universities' students enrolled in the "double degree" program, presented papers on the subject of research at the partner universities. The best 3 papers presented in this journal.
} 
area or within bounds of only one technology does not worth it. Researchers should keep track of new technologies appearance and improvements in competing areas.

Methods of scientific and technical work and technology forecasting, when used together, allow to discover areas that are already at the border of a new phase of development and also to make an analysis of possible alternatives and solutions. Consequently this can force appearance of new practice-oriented solutions and of innovations in the result of implementation.

\section{Methodology of modelling of dynamic situations with the help of subjective models (cognitive maps)}

For «soft» systems analysis P. Checkland [4] suggested methodology of «soft» system analysis, which represents system-oriented guidance that helps analytics to manage with analysis of complex situations. Task of decision making supporting in controlling «soft» dynamic situation is a task of developing a strategy to move situation from current condition into a goal condition on basis of subjective model of situation. This subjective model includes expert-estimated values of factors and model of functional structure, which describes known to analytic law of variation and principles of observed situation. This subjective model is represented as a directed graph, which is called cognitive map [3].

\section{Building a Cognitive Map}

This stage consists in picking out the set of describing situation factors and determining cause-and-effect relations among them. This expert procedure depends much on expert's knowledge and preferences.

Cognitive map $(\mathrm{O}, \mathrm{W})$ is determined by set of factor nodes of situation $\mathrm{O}$ and adjacency matrix of directed graph $W=\left|w_{i j}\right|$.

Scientific significance, advancement of scientific projects, and expected results can be estimated with formal methods on the stage of innovative project development. Formally economical mathematical model can be described with measurable parameters.

From the analysis considering economical mathematical model of innovation project [5] it can be concluded that factors represented in table 1 should be selected.

\section{Factors and indicators of innovative process estimation on the development stage [9]}

\begin{tabular}{|c|c|}
\hline Factor & Indicator \\
\hline $\begin{array}{l}\text { 1. Research } \\
\text { activity }\end{array}$ & - $\quad$ Russian journals' reputation by SJ R (according to SCOPUS data). ( $\mathrm{O}_{6}$ ). \\
\hline $\begin{array}{l}\text { 2. Technology } \\
\text { support }\end{array}$ & $\begin{array}{l}\text { - Financing of Russian Humanitarian Scientific Fund from federal } \\
\text { budgetary funds (in millions of rubbles) [20]. }\left(\mathrm{O}_{4}\right) \text {. } \\
\text { - } \\
\text { Scientific research financing from federal budgetary funds (in millions of } \\
\text { rubbles) [12-19]. }\left(\mathrm{O}_{5}\right) \text {. }\end{array}$ \\
\hline $\begin{array}{l}\text { 3. Number of } \\
\text { developments } \\
\text { (applications) }\end{array}$ & $\begin{array}{ll}\text { - } & \text { Number of applications for the grant of a patent in Russia [12-19]. }\left(\mathrm{O}_{1}\right) \text {. } \\
\text { - } & \text { Number of applications for the grant of a patent in Russia, which were } \\
\text { - } & \text { Nubmitted by Russian applicants [12-19]. }\left(\mathrm{O}_{2}\right) \text {. } \\
\text { - } & \text { submitted of by foreign applicants [12-19]. }\left(\mathrm{O}_{8}\right) \text {. } \\
\text { - } & \text { Number of applications for the grant of a patent in USA [21]. }\left(\mathrm{O}_{7}\right) \text {. }\end{array}$ \\
\hline $\begin{array}{l}\text { 4. Development } \\
\text { of technology }\end{array}$ & - $\quad$ Number of applications, submitted for RHSF competitions [20]. \\
\hline
\end{tabular}

Approach based on cognitive maps is used to describe interconnections among factors. Then the parameters, which are the nodes of cognitive map and degrees of their interactions, are accounted with edges (figure 1). 


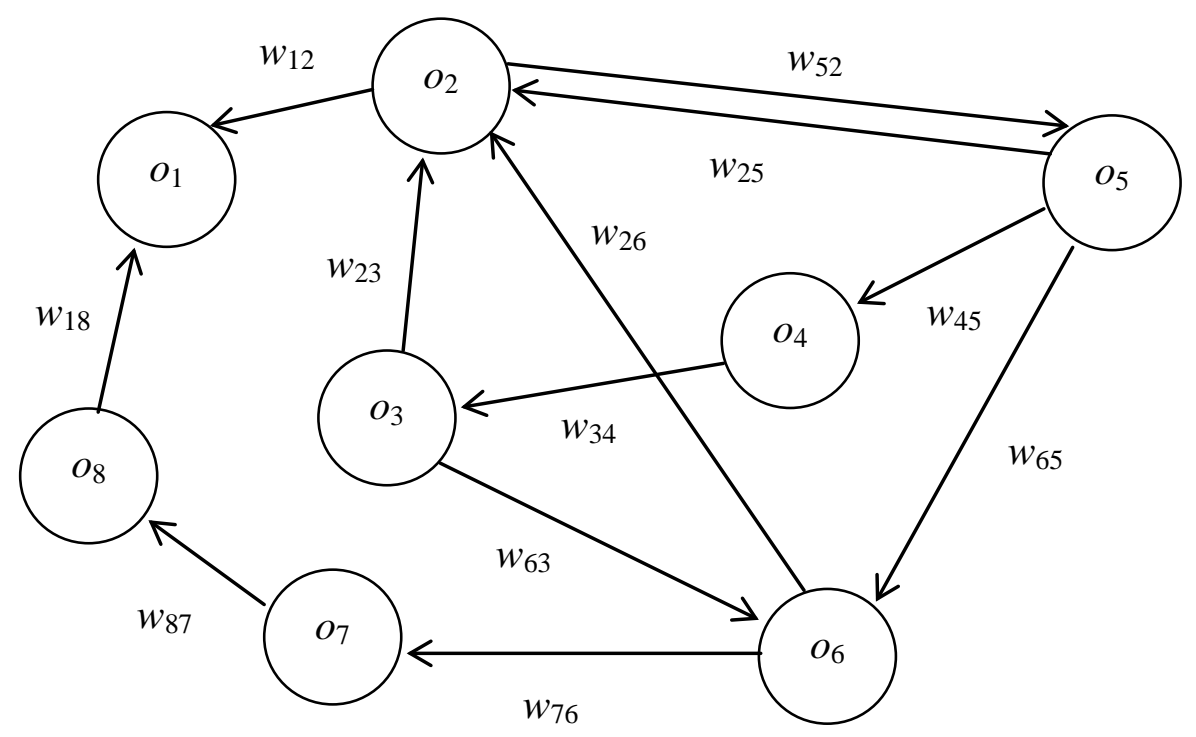

Fig. 1. Cognitive map of innovative activity

\section{Cognitive Map Parameterization}

It is necessary to determine weighting coefficient values $\left(w_{i j}\right)$ in order to use the cognitive map in calculations and choose algorithm for calculation of new factors values.

Statistical data for each factor used for building innovative activity model for 2004-2011 years is presented in table 2 .

Statistical data for 2004-2011 years

Table 2.

\begin{tabular}{|c|c|c|c|c|c|c|c|c|}
\hline Year & $\mathbf{2 0 0 4}$ & $\mathbf{2 0 0 5}$ & $\mathbf{2 0 0 6}$ & $\mathbf{2 0 0 7}$ & $\mathbf{2 0 0 8}$ & $\mathbf{2 0 0 9}$ & $\mathbf{2 0 1 0}$ & $\mathbf{2 0 1 1}$ \\
\hline & 0 & 1 & 2 & 3 & 4 & 5 & 6 & 7 \\
\hline $\mathrm{O}_{1}$ & 42593 & 45644 & 51775 & 54337 & 57555 & 53457 & 58759 & 58852 \\
\hline $\mathrm{O}_{2}$ & 33954 & 35242 & 39776 & 39835 & 40551 & 38298 & 42460 & 40992 \\
\hline $\mathrm{O}_{3}$ & 5137 & 5683 & 7783 & 6841 & 7500 & 8395 & 9313 & 9349 \\
\hline $\mathrm{O}_{4}$ & 594 & 605 & 717 & 890 & 1100 & 1164 & 1000 & 1000 \\
\hline $\mathrm{O}_{5}$ & 47478 & 76909,3 & 97363,2 & 132703 & 162116 & 219058 & 237657 & 313899 \\
\hline $\mathrm{O}_{6}$ & 0,152 & 0,164 & 0,1705 & 0,18925 & 0,19975 & 0,21475 & 0,21375 & 0,2505 \\
\hline $\mathrm{O}_{7}$ & 84270 & 74637 & 89823 & 79526 & 77502 & 82382 & 107792 & 108626 \\
\hline $\mathrm{O}_{8}$ & 8639 & 10302 & 11999 & 14502 & 17004 & 15159 & 16299 & 17860 \\
\hline
\end{tabular}

Factors are described by values of different dimensions (R\&D financing in millions of rubbles, citing index in dimensional quantity as a decimal fraction). In order to operate with values of the same order, it is necessary to make scaling of factors' values $o_{i}(t)$.

Normalization of input data is a process, in which all input data are leveled, that is a reduction to interval $[0,1]$ is done.

Without normalization values of «R\&D financing» factor will have significantly greater influence to a target factor than values of «citation index» factor. After normalization dimensions of all input and output data are reunited.

General view of normalization formula: 
where $\mathrm{x}$ - value to be normalized;

$$
x_{\text {норм }}=\frac{\left(x-x_{\min }\right)\left(d_{2}-d_{1}\right)}{x_{\max }-x_{\min }}+d_{1},
$$

$\left[x_{\min }, x_{\max }\right]$ - an interval of $x$ values;

$\left[d_{1}, d_{2}\right]$ - an interval, to which reduction of $x$ values is done.

Adjacency matrix of directed graph is presented in formula:

$$
W=\left[\begin{array}{cccccccc}
0 & w_{12} & 0 & 0 & 0 & 0 & 0 & w_{18} \\
0 & 0 & w_{23} & 0 & w_{25} & w_{26} & 0 & 0 \\
0 & 0 & 0 & w_{34} & 0 & 0 & 0 & 0 \\
0 & 0 & 0 & 0 & w_{45} & 0 & 0 & 0 \\
0 & w_{52} & 0 & 0 & 0 & 0 & 0 & 0 \\
0 & 0 & w_{63} & 0 & w_{65} & 0 & 0 & 0 \\
0 & 0 & 0 & 0 & 0 & w_{76} & 0 & 0 \\
0 & 0 & 0 & 0 & 0 & 0 & 0 & w_{87}
\end{array}\right]
$$

Thereby cognitive map $(\mathrm{O}, \mathrm{W})$ is described with set of situation factors-nodes $\mathrm{O}$ and adjacency matrix of directed graph $W=\left|w_{i j}\right|$.

Cognitive map nodes are considered as neurons in neural networks and described with function $\mathrm{O}_{\mathrm{i}}$. It is done in order to minimize error accumulation in the result of expert estimations. As function $\mathrm{O}_{\mathrm{i}}$ the following recurrent formula can be used [8]:

$$
o_{i}(t)=\frac{1}{1+\exp \left(-\sum_{j} w_{i j} \cdot o_{j}(t-1)\right)}
$$

For determining weighting coefficients values $\mathrm{w}_{\mathrm{ij}}$ the equations for eight nodes are transformed into the view of the following formula:

$$
\sum_{j} w_{i j} \cdot o_{j}(t-1)=-\ln \left(\frac{1-o_{i}(t)}{o_{i}(t)}\right)
$$

As there are three unknown quantities in the equation for the node $\mathrm{O}_{2}$, it is necessary to write down weighting coefficients equation three times for different time points (t and $t-1)$, ( $t-1$ and $t-2)$ and ( $t-2$ and $t-3$ ), which are shifted on one time point from each other. For nodes $\mathrm{O}_{1}$ and $\mathrm{O}_{6}$ equations are written in the same way. In result we have eleven equations for twelve unknown variables. These combined equations are presented by the following formula: 


$$
\left\{\begin{array}{l}
w_{12} \cdot o_{2}(t-1)+w_{18} \cdot o_{8}(t-1)=-\ln \left(\frac{1-o_{1}(t)}{o_{1}(t)}\right) \\
w_{12} \cdot o_{2}(t-2)+w_{18} \cdot o_{8}(t-2)=-\ln \left(\frac{1-o_{1}(t-1)}{o_{1}(t-1)}\right) \\
w_{23} \cdot o_{3}(t-1)+w_{25} \cdot o_{5}(t-1)+w_{26} \cdot o_{6}(t-1)=-\ln \left(\frac{1-o_{2}(t)}{o_{2}(t)}\right) \\
w_{23} \cdot o_{3}(t-2)+w_{25} \cdot o_{5}(t-2)+w_{26} \cdot o_{6}(t-2)=-\ln \left(\frac{1-o_{2}(t-1)}{o_{2}(t-1)}\right) \\
w_{23} \cdot o_{3}(t-3)+w_{25} \cdot o_{5}(t-3)+w_{26} \cdot o_{6}(t-3)=-\ln \left(\frac{1-o_{2}(t-2)}{o_{2}(t-2)}\right) \\
w_{34} \cdot o_{4}(t-3)=-\ln \left(\frac{1-o_{3}(t)}{o_{3}(t)}\right) \\
w_{45} \cdot o_{5}(t-3)=-\ln \left(\frac{1-o_{4}(t)}{o_{4}(t)}\right) \\
w_{52} \cdot o_{2}(t-1)=-\ln \left(\frac{1-o_{5}(t)}{o_{5}(t)}\right) \\
w_{63} \cdot o_{3}(t-1)+w_{65} \cdot o_{5}(t-1)=-\ln \left(\frac{1-o_{6}(t)}{o_{6}(t)}\right) \\
w_{63} \cdot o_{3}(t-2)+w_{65} \cdot o_{5}(t-2)=-\ln \left(\frac{1-o_{6}(t-1)}{o_{6}(t-1)}\right) \\
w_{76} \cdot o_{6}(t-1)=-\ln \left(\frac{1-o_{7}(t)}{o_{7}(t)}\right) \\
o_{7}(t-1)=-\ln \left(\frac{1-o_{8}(t)}{o_{8}(t)}\right)
\end{array}\right.
$$

In order to solve the combined equations a Gauss method can be used:

$$
X=A^{-1} \cdot B
$$

where A and B - matrices describing combined equations (5), X - matrix containing calculated weighting coefficients values $w_{i j}$.

Calculated weighting coefficients values $w_{i j}$. for four iterations are presented in table 3 .

Table 3.

\section{Calculated values of weighting coefficients $w_{i j}$}

\begin{tabular}{|c|c|c|c|c|c|}
\hline Year & 2008 & 2009 & 2010 & 2011 & 2012 \\
\hline Iteration number & 1 & 2 & 3 & 4 & 5 \\
\hline $\mathrm{W}_{12}$ & $-3,1811$ & $-0,456$ & 3,1798 & 9,0855 & $-2,3368$ \\
\hline $\mathrm{w}_{18}$ & 5,4863 & 1,6865 & $-2,514$ & $-8,438$ & 3,7000 \\
\hline $\mathrm{W}_{23}$ & $-1,6110$ & $-0,047$ & $-1,292$ & $-36,86$ & $-3,6102$ \\
\hline $\mathrm{w}_{25}$ & 5,3875 & $-0,269$ & $-3,32$ & 11,817 & 3,5417 \\
\hline $\mathrm{W}_{26}$ & 0,6453 & 1,31 & 4,2226 & 30,206 & 2,1112 \\
\hline $\mathrm{W}_{34}$ & $-0,1186$ & 0,2737 & 0,6346 & 1,0224 & 1,2102 \\
\hline $\mathrm{W}_{45}$ & 0,1884 & 1,8885 & 2,0132 & 0,6298 & 0,5806 \\
\hline $\mathrm{W}_{52}$ & $-1,4977$ & $-1,03$ & $-0,219$ & 0,0315 & 1,0397 \\
\hline $\mathrm{W}_{63}$ & 5,9433 & $-0,397$ & $-2,183$ & 0,9034 & 26,8135 \\
\hline $\mathrm{W}_{65}$ & $-15,8809$ & 1,1362 & 4,2272 & $-0,567$ & $-33,9059$ \\
\hline
\end{tabular}




\begin{tabular}{|c|c|c|c|c|c|}
\hline $\mathrm{W}_{76}$ & $-0,1052$ & $-0,194$ & 0,0421 & 1,1727 & 1,2185 \\
\hline $\mathrm{W}_{87}$ & 0,3005 & 1,132 & 0,557 & 0,8714 & 1,0478 \\
\hline
\end{tabular}

\section{Application of cognitive modeling for technological forecasting}

Suggested model on the basis of cognitive map allows to get forecast for one forward step. Statistical data for three previous iterations are sufficient for calculating factors values by analytical method with formula (3).

In order to make strategic forecast we need to know law of model coefficients variation.

New model coefficients values can be calculated when new statistical data for factors appears and dynamics can be analyzed. If we know law of variation, weighting coefficients values can be extrapolated and we can make forecast for several forward steps.

We suggest that weighting coefficients changing can be described with linear regression model represented by the following formula:

$$
y=a+b \cdot x
$$

For each weighting coefficient of cognitive map we develop linear regression models on the basis of three and four previous iterations. Regression model coefficients are calculated with leastsquares method.

We can judge about model adequacy by determining the size of error [10]. We denote the experimental function by $\mathrm{Y}_{\mathrm{E}}$, theoretical function by $\mathrm{Y}_{\mathrm{T}}$ and number of experimental points by $\mathrm{n}$. The hypothesis can be accepted, if conditions are fulfilled: $68 \%$ of experimental points and more should be in interval $\left(Y_{T}-\sigma \leq Y_{E} \leq Y_{T}+\sigma\right)$ and $95 \%$ of points should be in interval $\left(Y_{T}-2 \sigma \leq Y_{E} \leq Y_{T}+2 \sigma\right)$. If not we should suggest a more complex hypothesis. Value $\sigma$ can be calculated with the following formula:

$$
\sigma=\sqrt{\frac{\sum_{i=1}^{n}\left(Y_{i}^{T}-Y_{i}^{\ni}\right)^{2}}{n}}
$$

For each weighting coefficient of cognitive map we developed models on the basis of three previous iterations and value for the fourth iteration was forecasted. Then we developed models on the basis of four previous iterations and value for the fifths iteration was forecasted. Real coefficient values, regression models built on the basis of three and four previous iterations and forecasted values are presented in figure 2 .

By the models presented in figure 2 we can judge that weighting coefficients models become more accurate, when new statistical data appear.

But evidently not all coefficient values can be described with linear regression models. We can make hypotheses more complex and describe coefficients with polynomials of second and third degree:

$$
\begin{gathered}
y=a c * b x+2 \\
y=a c * b x d x^{2}+3
\end{gathered}
$$

These three hypotheses are sufficient for describing statistical data. The built models were tested with the criteria mentioned above and are adequate to weighting coefficients values calculated by analytical method.

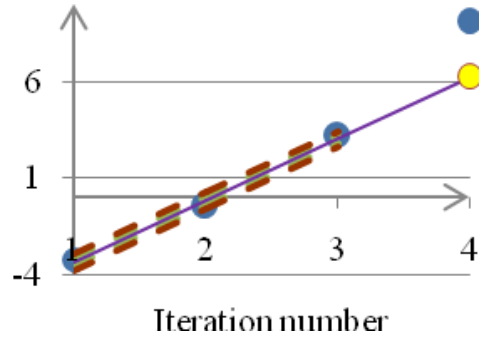

a

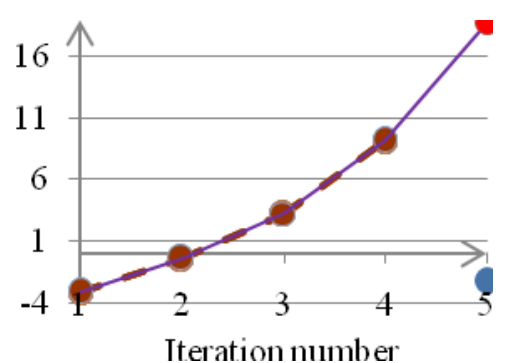

$\mathrm{b}$

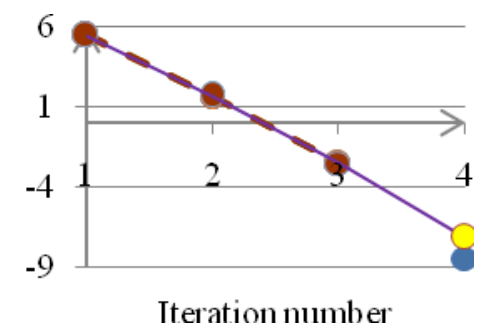

C 


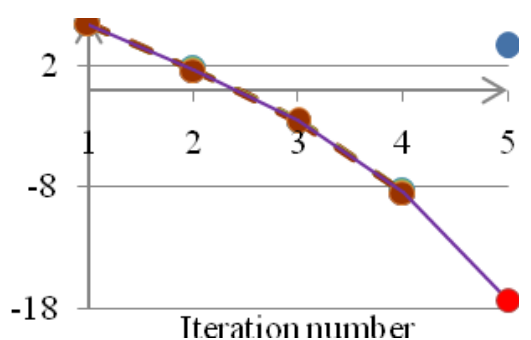

d

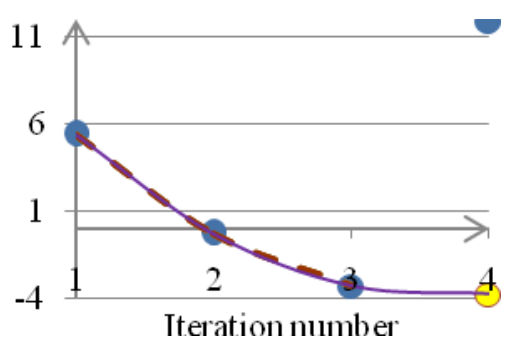

g

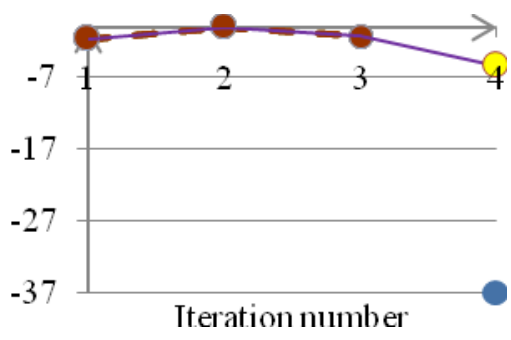

$\mathrm{e}$

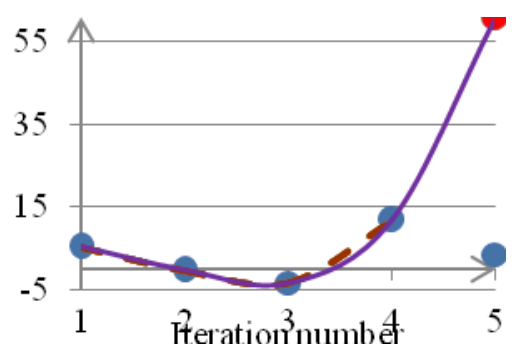

$\mathrm{h}$

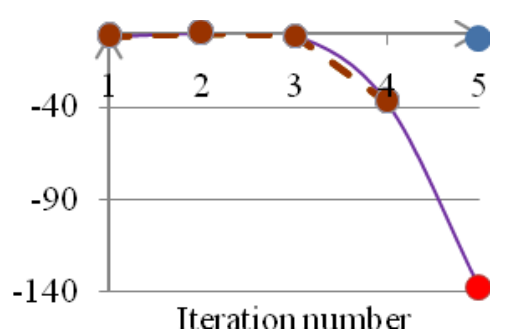

$\mathrm{f}$

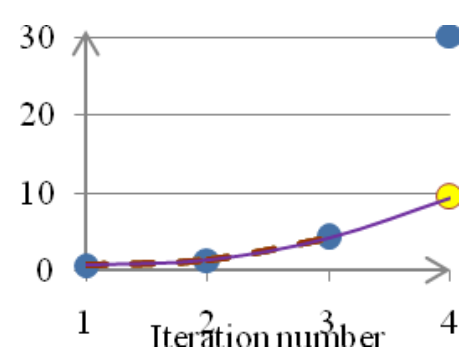

i

Weighting coefficients values $\mathrm{w}_{\mathrm{ij}}$, calculated by analytical method

Weighting coefficients values $\mathrm{w}_{\mathrm{ij}}$, predicted on regression model, which was built on the basis of three previous iteration values

- Weighting coefficients values $\mathrm{w}_{\mathrm{ij}}$, predicted on regression model, which was built on the basis of four previous iteration values

Regression model

- Interval $\left[\mathrm{Y}_{\mathrm{T}}-\sigma ; \mathrm{Y}_{\mathrm{T}}+\sigma\right]$ for regression model

_ _ _ Interval [ $\left.\mathrm{Y}_{\mathrm{T}}-2 \sigma ; \mathrm{Y}_{\mathrm{T}}+2 \sigma\right]$ for regression model

Fig. 2. Regression models of cognitive map weighting coefficients $w_{i j}$

Values dynamics and regression models of the following coefficients: $\mathrm{w}_{12}$ : $\mathrm{a}$ - built on the basis of three iterations, $\mathrm{b}$ - built on the basis of four iterations; $\mathrm{w}_{18}$ : $\mathrm{c}$ - built on the basis of three iterations, $d$ - built on the basis of four iterations; $w_{23}$ : $e$ - built on the basis of three iterations, $f$ built on the basis of four iterations; $w_{25}: g$ - built on the basis of three iterations, $h$ - built on the basis of four iterations; $\mathrm{w}_{26}$ : $\mathrm{i}$ - built on the basis of three iterations, $\mathrm{j}$ - built on the basis of four iterations; $\mathrm{w}_{34}: \mathrm{k}$ - built on the basis of three iterations, $\mathrm{l}$ - built on the basis of four iterations; $\mathrm{w}_{45}: \mathrm{m}$ - built on the basis of three iterations, $\mathrm{n}$ - built on the basis of four iterations; $\mathrm{w}_{52}$ : $\mathrm{O}$ - built on the basis of three iterations, $p$ - built on the basis of four iterations; $w_{63}$ : $q$ - built on the basis of three iterations, $r$ built on the basis of four iterations; $\mathrm{w}_{65} \mathrm{~s}$ - built on the basis of three iterations, $\mathrm{t}$ - built on the basis of four iterations; $\mathrm{w}_{76}$ : $\mathrm{u}$ - built on the basis of three iterations, $\mathrm{v}$ - built on the basis of four iterations; $\mathrm{w}_{87} \mathrm{~W}$ - built on the basis of three iterations $\mathrm{x}$ - built on the basis of four iterations.

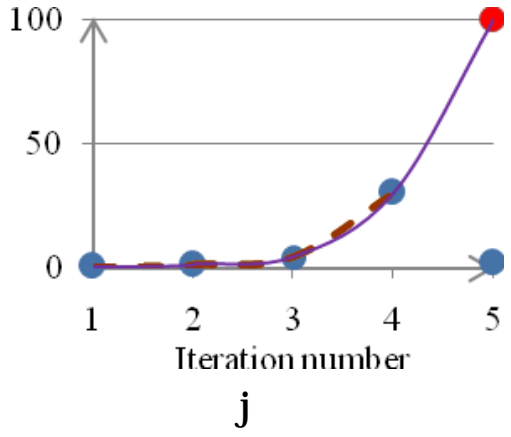

j

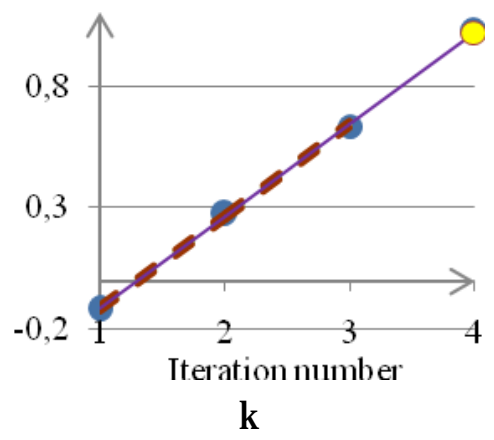

$\mathrm{k}$

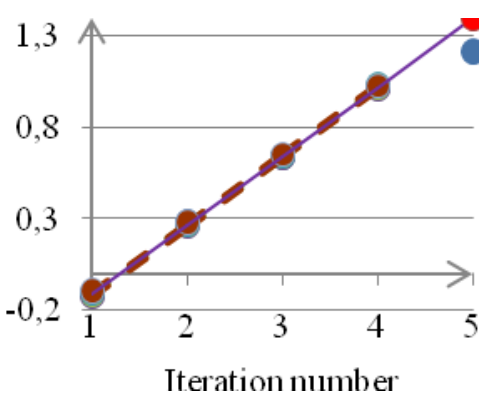

1 


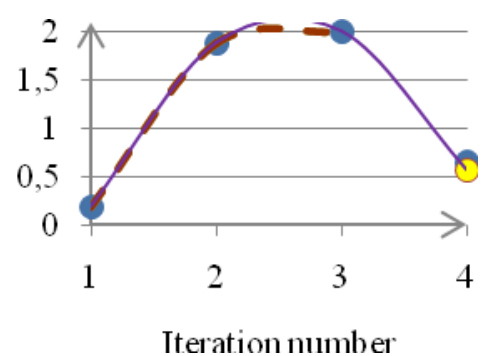

$\mathrm{m}$

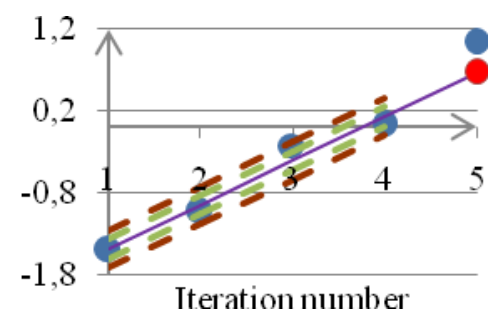

$\mathrm{p}$

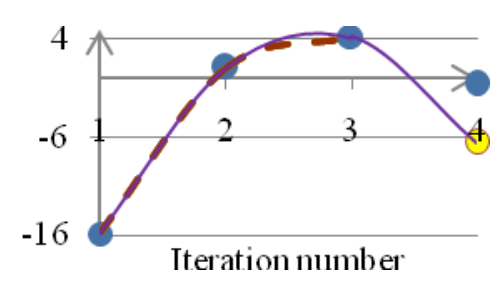

S

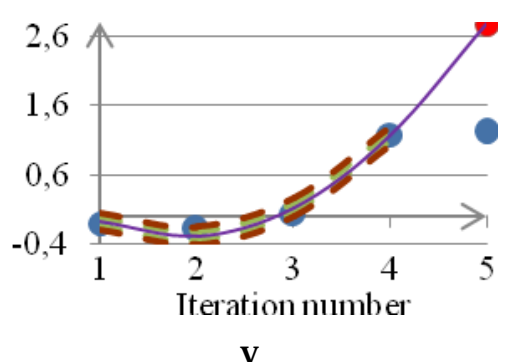

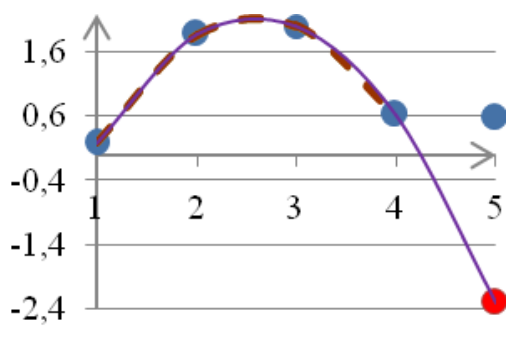

Iteration number

$\mathrm{n}$

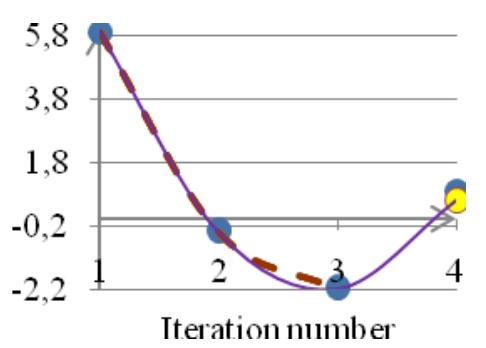

q

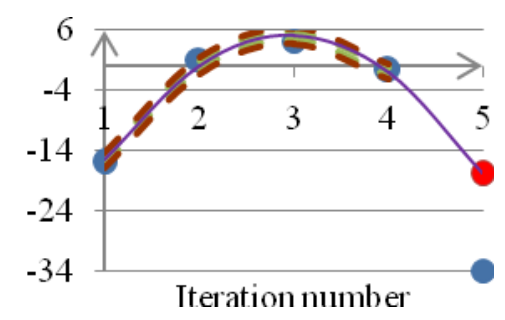

$\mathrm{t}$

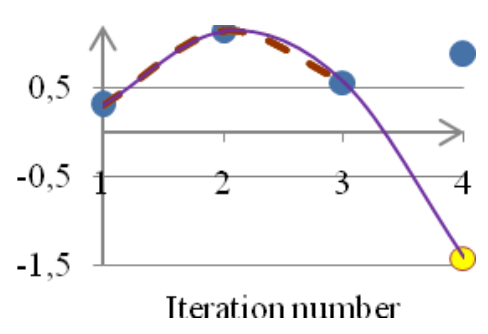

$\mathrm{W}$

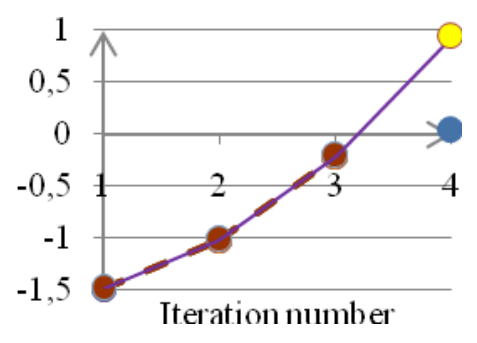

o

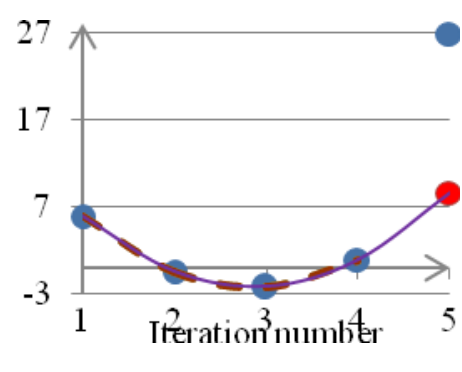

$r$

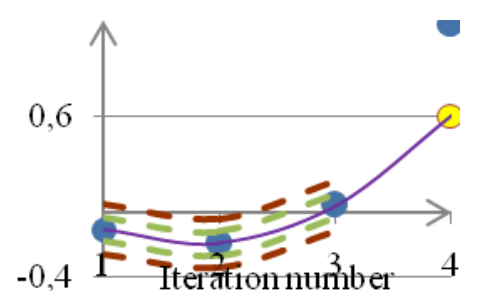

$\mathrm{u}$

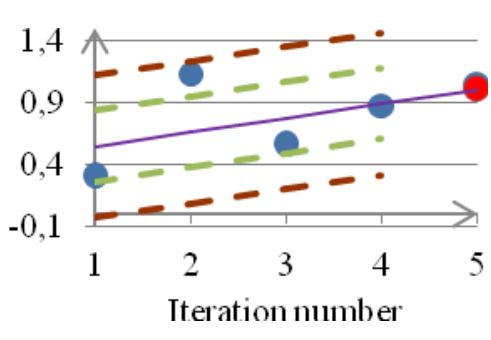

$\mathrm{X}$

Continuation of Figure 2

Produced calculations reveal several features related to cognitive map link coefficients calculations by regression method (some of weighting coefficients and factors differ from the other values in series, e.g. in figures $2-d, f, h, v)$.

First of all, little amount of statistical data significantly influences mathematical formulation even by marginal changes. There by local character, but not global tendencies can be accounted. Increase of statistical data amount or separation of noisy data can solve this problem.

Secondly, when calculating by analytical method the model accounts many influencing each other factors, and errors of estimation, related to values rounding and errors in statistics gathering, accumulate.

When developing regression models, analytical data are used and there is probability of large generalization errors, which is conditional on analytical weighting coefficients calculation method itself and connected with possibility of error accumulation.

Thereby there is a problem of separation statistical data, which bring statistical errors. Separation can be done by calculating the confidence intervals. When developing extrapolation function, according to normal distribution law $68 \%$ of data points should be situated in interval $\sigma$, $95 \%$ of data points in interval $2 \sigma$ and $99 \%$ of data points in interval $3 \sigma$. Economic and socio- 
economic systems are described with fractal regularities, which are reflected in self-similarity of system elements. So deviation of valid data from previous values should be in interval $\sigma$, when using two previous valid data points' values.

Results of calculations of forecast values are presented in table 4.

Table 4.

Real factors values and predicted factors values, calculated by analytical method and regression model

\begin{tabular}{|c|c|c|c|c|c|c|}
\hline & \multicolumn{2}{|l|}{ Real factors values $O_{\mathrm{i}}$} & \multicolumn{2}{c|}{$\begin{array}{c}\text { Factors values } O_{\mathrm{i}} \text { calculated } \\
\text { by analytical method }\end{array}$} & $\begin{array}{c}\text { Factors values } O_{\mathrm{i}} \text {, calculated } \\
\text { with regression models }\end{array}$ \\
\hline Year & 2011 & 2012 & 2011 & 2012 & 2011 & 2012 \\
\hline$O_{1}$ & 0,6667 & - & 0,7157 & 0,7236 & 0,4537 & 0,6101 \\
\hline$O_{2}$ & 0,6436 & - & 0,2086 & 0,7961 & 0,4732 & 1 \\
\hline$O_{3}$ & 0,6667 & - & 0,6424 & 0,6667 & 0,5908 & 0,69 \\
\hline$O_{4}$ & 0,5727 & - & 0,5788 & 0,5956 & 0,5721 & 0,1766 \\
\hline$O_{5}$ & 0,6667 & - & 0,5053 & 0,6613 & 0,652 & 0,6065 \\
\hline$O_{6}$ & 0,6667 & - & 0,5779 & 0,0088 & 0,0497 & 0,0022 \\
\hline$O_{7}$ & 0,6667 & - & 0,6608 & 0,6926 & 0,5849 & 0,8641 \\
\hline$O_{8}$ & 0,6667 & - & 0,6403 & 0,6679 & 0,2809 & 0,6609 \\
\hline
\end{tabular}

\section{Conclusions}

The suggested forecast model on the basis of dynamic cognitive map can be used in controlling the process of scientific research and development. Dynamic cognitive map can be used as information support in the process of managing of scientific research guidelines and making analysis of considered technology application field and its geographical spreading.

Parameters dynamics monitoring facilitates successful innovative activity controlling [22].

The suggested dynamic cognitive map forecast model can be used in controlling the process of scientific research and development. Dynamic cognitive map can be used as information support in controlling research guidelines and analysis of considered technology application fields and geographical spreading.

Considered approach can be used for conceptual analysis and modeling of complex and illdefined political, economic and social situations, developing strategies of business development, and also for continuous situation state monitoring and verifying hypotheses about situation development and control mechanism [87]. It is important that your conclusion provides a summary of the achievements, further work needed and recommendations.

\section{References:}

1. Amberg M., Mylnikov L. Innovation project lifecycle prolongation method // Communications of the IBIMA. 2009. №3. pp. 11-15.

2. Armstrong J.S. Principles of Forecasting - A Handbook for Researchers and Practitioners. Kluwer Academic, 2001.

3. Axelrod R.. The Structure of Decision: Cognitive Maps of Political Elites. - Princeton: University Press, 1976.

4. Checkland P.B. System Thinking, Systems Practice. New York: Wiley, 1981.

Collopy F., ArmstrongJ .S. Rule-Based Forecasting: Development and Validation of an Expert Systems Approach to Combin-ing Time Series Extrapolations // Management Sci., 1992. №10(38). pp. 1394-1414.

5. Delurgio S.A. Forecasting Principles and Applications. - Boston: Irwin McGraw-Hill, 1998.

6. Easingwood, C.J., Mahajan V., Muller E.A. Nonuniform Influence Innovation Diffusion Model of New Product Acceptance // Marketing Science, 1983. №2, pp. 273-295.

7. Köller R. Konstructionsmethode für den Mashinen-, Geräte- und Apparatebau. Berlin Heidelberg - New-York: Springer - Verlag, 1976.8. Murat Bengisu, Ramzi Nekhili. Forecasting 
emerging technologies with the aid of science and technology databases // Technological Forecasting and Social Change. 2006. № 73. P. 835-844.

9. Kulinich A.A. Computer systems of decision-makin g support in ill-structured dynamic situations, based on modeling of the expert knowledge presented by cognitive maps are considered. Methods and approaches of the basic functional subsystems realization of decision-making support systems of this class are analysed // Control science. 2010. №3. pp. 2-16. (in Russian) Russian)

10. Mylnikov L.A., Trushnikov D.N. Simulation systems. Perm: PSTU, 2006. 42 p. (in

11. Robert J. Wattse, Alan L. Porter Innovation forecasting/Technological Forecasting and Social Change. Volume 56, Issue 1, 1997. pp. 25-47.

12. Sokolkin V.L. Russian Statistical Yearbook. Moscow: Federal State Statistics Service, 2005. (in Russian)

13. Sokolkin V.L. Russian Statistical Yearbook. Moscow: Federal State Statistics Service, 2006. (in Russian)

14. Sokolkin V.L. Russian Statistical Yearbook. Moscow: Federal State Statistics Service, 2007. (in Russian)

15. Sokolkin V.L. Russian Statistical Yearbook. Moscow: Federal State Statistics Service, 2008. (in Russian)

16. Sokolkin V.L. Russian Statistical Yearbook. Moscow: Federal State Statistics Service, 2009. (in Russian)

17. Surinov A.E. Russian Statistical Yearbook. Moscow: Federal State Statistics Service, 2010. (in Russian)

18. Surinov A.E. Russian Statistical Yearbook. Moscow : Federal State Statistics Service, 2011. (in Russian)

19. Surinov A.E. Russian Statistical Yearbook. Moscow: Federal State Statistics Service, 2012. (in Russian)

20. The activities of the Russian Foundation for the Humanities in 2011 (report), 2012.

21. U.S. Patent And Trademark Office Patent Technology Monitoring Team Report, 2013.

22. Watts R.J., Porter A.L. Innovation forecasting // Technological Forecasting and Social Change. 1997. Vol. 56, Issue 1. P. 25-47. 